\title{
The Research of Reform and Innovation of Tourism Enterprise Human Resources Management in Knowledge Economy
}

\author{
Yu Nan \\ Yellow River Conservancy Technical Institute, 475004 \\ hunter2011@foxmail.com
}

Keywords: Knowledge Economy, Tourism Enterprise, Human Resources Management, Reform and Innovation

\begin{abstract}
With the advent of the knowledge economy era, the management mode and management concept of corporate human resources have undergone profound changes and faced many challenges. Tourism business, as a strong sensitivity business, it is bound to be seriously affected by the environment. Therefore, tourism enterprises want to achieve better development, they must strengthen the innovation and reform of human resources management. Based on this, this paper analysis the challenges faced by human resource management in the knowledge economy and propose appropriate innovation and reform countermeasures of tourism business human resources management.
\end{abstract}

\section{Introduction}

Human society has experienced agricultural economy and industrial economy and now is moving to a new era of knowledge economy. Knowledge-based economy is built on knowledge, information production, distribution and use of the economy. In the knowledge economy, knowledge and innovation is to determine the decisive source of economic growth, and people as the master, the carrier of innovation and knowledge development, human resources as the most important factor of production. The rise of the knowledge economy, so that people working increased flexibility, increased leisure time, income increase, bringing new travel consumer demand and market opportunities. Meanwhile, due to the world economic integration, tourism enterprises will increasingly fierce competition. Tourism enterprises are labor-intensive industries, in order to provide service-oriented, competitive tourism enterprises is essentially talent competition. Therefore, tourism enterprises to maintain a strong competitive edge in the knowledge economy, the knowledge economy research human resource development and management must be strengthened [1].

\section{The Management Objectives of Tourism Enterprise Human Resource}

Tourism Human Resource Management and Development is through corporate human resources for effective use, management, mining and incentives to get the optimal combinations and maximum enthusiasm to play to ensure the efficient functioning of the enterprise, to provide quality services, improve enterprise economic and social benefits. Specifically, tourism enterprise human resource management objectives include three aspects: (1) to create a high-quality workforce. (2) to achieve the optimal combination of staff and can make the best use of the staff. (3) the establishment of a system of human resource development and utilization, form optimization mechanism for talented people to create a good working environment, and fully mobilize the enthusiasm and creativity of employees [2].

\section{The New Demands for Tourism Enterprise Human Resource Management in Knowledge} Economy

Knowledge economy has brought new changes in the resource structure of tourism enterprise. The knowledge economy material and financial resources are still an important business 
resource, but the most important resource is the knowledge and information resources. Because people are producing knowledge, impart subject knowledge and application of knowledge, human resources and thus will become the soul of the economy. Knowledge economy tourism enterprises must implement people-oriented strategy, business investment should focus on that human resource development, strengthen personnel training, improve the quality and innovation capacity of people to create and add value intangible assets, enhance their visibility.

Knowledge economy has brought new tourism competition. In knowledge economy, tourism enterprises will change from the traditional resource, source-based competition into knowledge, technology and information-based competition. The competition of tourism enterprises is the competition of knowledge and talent. In today's increasingly competitive international environment, enterprise survival and development of the core issues on the performance and quality of the competition to obtain human resources.

Knowledge economy calls for human resource management innovation. Innovation is the soul of the knowledge economy. General Secretary Jiang Zemin clearly pointed out: "Innovation is the soul of a nation's progress, is an inexhaustible motive force for national prosperity, a nation without innovation is difficult to stand in the nations of the world." Man is the subject of innovation, the development of knowledge, updates and applications are required to be done by the people. For tourism employees, its spirit of innovation and creativity is a special resource and they can under no precedent in the case, in practice, constantly enriched, control and use of innovative knowledge. Therefore, enterprises in Human Resource Management It should also be innovative. Enterprises should implement effective and targeted human resources management, enterprise management to change the traditional mode of relying too much on monitoring, instructions, orders and other rigid management style, employee motivation innovative initiative to provide a loose to play to their innovation capability the environment and atmosphere [3].

\section{The Challenges of Tourism Enterprise Human Resource Management in the Knowledge Economy}

The challenges from the economic globalization. With the development of science and technology and society, there is more frequent knowledge exchange between countries, gradually moving in the direction of international business development. Knowledge-based enterprises to promote the development of cross-border economic globalization, strengthening of human resource management, help to promote transnational enterprises, global business objectives. Tourism is across cultural and national boundaries and cultural activities, tourism staff human resource management departments need to have more global thinking, increase the value of human resource management. Enterprises should develop according to their own needs, building human resource management and organizational structure consistent with the needs of enterprise development, and create favorable conditions for enterprises to transnational cooperation. As international competition intensifies, companies must allocate resources on a global scale, but human resources is one of the important works. In the process of human resource management, human resource management and training difficulty increase, intercultural management and conflict between different cultures are to be solved. The traditional human resource management is only for small-scale enterprises in terms of the independence of the poor, unable to cope with these problems.

The challenges from the information network. Knowledge economy and information economy closely linked with the development and application of information technology, human resource management also shifted from the traditional information management. In the current human resources management under the information age, it is often required to use computers and the Internet to achieve, such as production, consumption and distribution aspects of information management. The application of information technology has changed the business management and economic operation mode. According to production requirements, restructuring and reengineering business to form a new management procedures, management methods and management standards. Development of information technology has a big impact of the traditional concept of time and space, 
to develop a new working environment and vision. Development of knowledge economy, tourism enterprise human resource management theory and practice of new challenges, new tools and methods of human resource management, to change the assessment of human resource management, recruitment, salary outlook, planning, forecasting, and training, etc. , promote human resource management models and theories [4].

The challenges from human resources management organization reform. With the development of knowledge economy, tourism businesses changes towards to flexible organizational reform, globalization, networking and diversified development. For businesses, the knowledge economy era represents the advancement of knowledge and technology, and promotes the reform of corporate organization and enterprise management organization has been improved. Improved organizational model helps to promote reform of the enterprise knowledge and technology and the two are mutually reinforcing interactions. Employees continue to improve the work environment and employees can combine their own development and business development, reasonable working hours, the use of telecommunications to office "moved back home", and "home office." Era of knowledge economy promote the reform of human resource organization mode. Meanwhile, information technology, economic globalization and the knowledge economy, derived from a variety of different virtual organizations. This virtual organization is led by a specialized agency in which members can communicate with each other within the structure of technology and knowledge, shared costs, and can fully meet with the customer needs. Virtual organization is very flexible, complementary features to help reduce organizational expenses, expanding the scope of services, improve work efficiency and quality, but also greatly reducing the product update cycle.

\section{The Reform and Innovation of Tourism Enterprise Human Resource Management in Knowledge Economy}

Take information management tools. In the knowledge economy, human resource management has change towards the direction of development of network information. Currently, many multinational companies have come to realize the importance of human resource information management. In the actual management and fully tap the human resources information management tools to enable the dynamic role of human resources into full play. It can share human resources, save technology development costs and enhance the company's competitive advantage. Tourism businesses need to build a sound human resources information system, use the system to store, analyze, acquire and transfer employees with relevant information, but also need to develop a reasonable human resource planning, rational prediction of human resources, to strengthen the evaluation and analysis, compensation and benefits analysis, recruitment management analysis and training analysis, and improving the resilience.

The implementation of personalized management mode. Enhance the cohesion of tourism employees is an important measure to promote tourism development, namely teamwork is the source and pillar to promote innovation and development. In the knowledge economy, human resources management has become an important part of corporate management, human resources management, often in the face "cooperation is more important than individual ability," the reality. How to enhance the team awareness of tourism employees? How to motivate the employees of solidarity and cohesion? At present, the tourism business employee needs more diversified, companies need to strengthen the importance of personalized management of human resources. With the emergence of virtual organizations, organizational structure towards the flat development, enterprise employees a sense of belonging and a sense of dependence enterprises gradually weakened, at the same time, the required staff and career development prospects to pursue diversification and personalization. Some employees of their enterprises gradually to job promotion and salary management mechanism appeared dissatisfied with meaning, and these subtle emotions, which are often caused by corporate executives of attention and focus, thus laying a contradiction. In order to attract more high-quality talent, tourism enterprises need to make the innovation of the task design methods, understand the 
interest of employees interested in, encourage employees to pursue their own ideals, their own design work duties, retain talent.

Establish flexible management measures. In the knowledge economy, human resource management is no longer carried out by the authority of rigid management tools and institutional constraints, mainly carried out through flexible management guide, motivate and inspire other means. Flexible Management has the speed and response, jumping and change, flexibility and sensitivity characteristics, based on humane management as the core. It focused on the creation and intuition, the value of the control element, equality and respect, initiative and entrepreneurial spirit. Through information sharing, complementary differences, virtual consolidation, virtual communities of practice, competitive cooperation, it can create more competitive advantage for enterprises. Tourism enterprises in carrying out flexible management, you need to pay attention to the following issues: according to the customer's needs and preferences determine the direction of management; virtual communities of practice are an important source of innovation; fully reflect the management of the basic functions, namely into the future, inspire and promote learning; Development Network type organization [5].

In carrying out the flexible management, we can take the following measures: First, to build a common vision, employee expectations and business development strategy together, so that employees generate a sense of mission, improve employee work passion. Secondly, the establishment of flexible work, quickly adapt to the knowledge economy era of flexible working hours, flexible working and complex work. Secondly, the fully authorized employee self-management, to enable them to maximize their talents, improve intelligence, self-worth, and ultimately achieve self-transcendence. Finally, build corporate culture of cooperation and innovative. Through the new corporate culture for employees to create a relaxed, open, harmonious working environment for enterprises to inject new vitality, fully stimulate potential employees, enhance employee cohesion.

\section{Conclusion}

In summary, in the era of knowledge economy, it is essential to strengthen the human resources management innovation and reform for enterprise development. In the process of tourism business human resource management, the enterprises should progressive and innovative management tools and management models and they should also take information management tools, the implementation of personalized management mode, set up flexible management mode.

\section{References}

[1] F.Zheng, Knowledge management and organizational design, Human Resources Management, 12(2008) 263-265.

[2] J.Zhang, Knowledge economy and the tourism, leisure industry in the 21st century, Tourism Tribune, 1(2008) 45-47.

[3] N.Y.Ma, How to do human resource management under the background of knowledge economy, Chinese E-commerce, 11(2014) 89-90.

[4] H.Y.Zhang, Technology and innovation of human resources management of power enterprise in the knowledge economy, Chinese E-commerce, 12(2014), 76-77.

[5] H.J.Zhu, Human resources management in the knowledge economy environment, Human Resources Management, 1(2015) 33-34. 